\title{
Employee Engagement and the Ethic of Friendship
}

\author{
Cam Caldwell ${ }^{1}$, Verl Anderson ${ }^{1} \&$ Marija Runic Ristic ${ }^{1}$ \\ ${ }^{1}$ American University in the Emirates, USA \\ ${ }^{2}$ Dixie State University, USA \\ Correspondence: Verl Anderson, Dixie State University, USA \\ Received: January 27, 2020 \\ Accepted: March 2, $2021 \quad$ Online Published: March 17, 2021 \\ doi:10.5430/bmr.v10n1p54 \\ URL: https://doi.org/10.5430/bmr.v10n1p54
}

\begin{abstract}
The failure of managers and supervisors to earn the trust and followership of the employees with whom they work is well documented in recent research about employee engagement (Clifton \& Harter, 2019). Without that employee commitment, organizations inevitably struggle to compete in the global marketplace and fail to achieve their potential (Cameron, 2012). Although much has been discussed in the light of the findings of concerned scholars (HR Research Institute, 2019), disagreement nonetheless exists about the factors which make up employee engagement, as well as the most effective approach that can be taken to increase engagement and those factors. Though there has not been full agreement about the nature of employee engagement, it is widely accepted that the failure of organizations to engage employees has been a serious deterrent to achieving organization results (Clifton \& Harter, 2019).
\end{abstract}

Objective: The purposes of this paper are to offer insights into the precise nature of employee engagement and to identify the value of employers adopting the Ethic of Friendship - an ethical perspective that has begun to be written about more frequently in the management literature.

Methods: We begin the paper by proposing an integrated and updated definition of employee engagement identifying nine factors which contribute to its makeup.

Results: We suggest that each of these nine factors significantly impact employee engagement and warrant increased attention by organizational leaders. We then address the Ethic of Friendship and its increasingly important role in today's arms-length and transactional relationship between employers and employees.

Conclusions: The paper then clarifies how the Ethic of Friendship addresses all nine of the factors which constitute employee engagement and explains how the Ethic of Friendship can increase the ability of organization leaders, managers, and supervisors to bridge the gap of distrust that often exists in the modern organization. After identifying five important contributions made by this paper, we conclude by encouraging leaders to adopt the Ethic of Friendship's commitment to treating employees as valued partners and, by so doing, create a culture in which employee engagement is likely to thrive.

Keywords: Ethic of Friendship, Employee Engagement, Friendship, Leadership, Transactional Relationships

\section{Introduction}

The failure of managers and supervisors to earn the trust and followership of the employees with whom they work is well documented in recent research about employee engagement (Clifton \& Harter, 2019). Without that employee commitment, organizations inevitably struggle to compete in the global marketplace and fail to achieve their potential (Cameron, 2012). Although much has been discussed in the light of the findings of concerned scholars (HR Research Institute, 2019), disagreement nonetheless exists about the factors which make up employee engagement, as well as the most effective approach that can be taken to increase engagement and those factors. Though there has not been full agreement about the nature of employee engagement, it is widely accepted that the failure of organizations to engage employees has been a serious deterrent to achieving organization results (Clifton \& Harter, 2019).

The purposes of this paper are to offer insights into the precise nature of employee engagement and to identify the value of employers adopting the Ethic of Friendship - an ethical perspective that has begun to be written about more frequently in the management literature. We begin the paper by proposing an integrated and updated definition of employee engagement - identifying nine factors which contribute to its makeup. We suggest that each of these nine factors significantly impact employee engagement and warrant increased attention by organizational leaders. 
We then address the Ethic of Friendship and its increasingly important role in today's arms-length and transactional relationship between employers and employees. The paper then clarifies how the Ethic of Friendship addresses all nine of the factors which constitute employee engagement and explains how the Ethic of Friendship can increase the ability of organization leaders, managers, and supervisors to bridge the gap of distrust that often exists in the modern organization. After identifying five important contributions made by this paper, we conclude by encouraging leaders to adopt the Ethic of Friendship's commitment to treating employees as valued partners and, by so doing, create a culture in which employee engagement is likely to thrive.

\section{Understanding Employee Engagement}

Employee engagement has been defined in various ways but is generally agreed to be "a desirable condition, (that) "has an organizational purpose, and connotes involvement, commitment, passion, enthusiasm, focused effort, and energy" (Macey \& Schneider, 2008, p. 4). It is correct to note, as recent scholars have reported (Clifton \& Harter, 2019; HR Research Institute, 2019; Saks \& Gruman, 2014), that employee engagement is demonstrated by extra-role behavior, the willingness to work hard, increased commitment, and employee creativity. Similarly, employee engagement is correlated with high levels of employee satisfaction, greater morale, an interest in taking on new responsibilities, and higher rates of employee retention (Beer, 2009).

Macey and Schneider (2008) have described engagement in terms of its impact on job satisfaction, organizational commitment, psychological empowerment, and job involvement. Erickson (2005) described engagement in term of the degree of an employee's willingness to invest personal effort in the pursuit of an organizational purpose - verbiage that is not dissimilar to the definition of the leader's effectiveness more than seven decades ago (Barnard, 1938).

Rather than parsing whether employee engagement is an affect, a psychological state, or simply a behavior, we suggest that it is more helpful to focus of employee engagement as a byproduct of the efforts of an organization's Top Management Teams, Human Resource Professionals (HRPs), and Managers and Supervisors as they create an organization culture and lead their organizations in promoting the engagement response.

Although much has been written about leaders' responsibilities in creating a work environment in which employees are highly invested partners (Schein \& Schein, 2016; Burns, 2010; Covey, 2004; Pfeffer, 1998), many who lead today's modern organizations apparently do not believe that investing in their relationships with employees is correlated with increasing employee commitment. The evidence from the extensive worldwide research by Gallup confirms that to achieve employees' high levels of personal commitment, it is critical that leaders and managers must accept their responsibility for establishing a work environment - together with aligned policies, programs and systems - that merit the trust and followership of their employees.

Instead of creating organizations which treat employees as valued assets, however, the growing trend in an overwhelming number of organizations has been to establish arms-length relationships wherein employees are relegated to the role of part-time or temporary agents to whom employers owe no long-term commitment or loyalty (Kopf, 2016). Instead of treating employees so well that they come to recognize their potential and strive to achieve it, as advocated by some scholars (Covey, 2004, p. 98), or honoring the "covenantal" obligations of servant leadership (DePree, 2004), the current trend of the past two decades has been to treat employees as cost centers rather than as owners and partners (Block, 2013).

Somehow, seemingly wise and competent executives and HRPs have failed to recognize that the top-down, high control, profit-first focus of yesteryear never really generated either high employee commitment or corporate success (Collins \& Porras, 2004). Although an abundance of evidence confirms that there are far more effective ways of increasing profitability, creativity, and competitive advantage (Dyer, Gregersen \& Christensen, 2019; Cameron, 2012), apparently many of today's leaders seem unable to adapt to the new requirements of today's global marketplace (Clifton \& Harter, 2019; Wickman, 2018).

We argue that the emphasis in understanding employee engagement must be on focusing on the responsibilities of an organization's leaders, rather than just on the responses of its employees. Organizations and their leaders must understand the root causes of employee engagement if they are realistically committed to obtaining the results of those causes. The evidence clearly affirms that employee engagement is a response to how they are treated and that many of today's leaders and supervisors seem to lack an understanding of the cause-and-effect relationships associated with their treatment of employees and those employees' responses.

We propose that employee engagement is enhanced when leaders incorporate nine relationship-based behaviors that frame the employer-employee relationship. Each of these behaviors requires the recognition that employees are far 
more than the easily replaced commodities apparently believed by many organization leaders. Moreover, we affirm the simple reality that people respond most effectively when treated humanely and with kindness.

\subsection{Emphasize Mission and Purpose}

The research about engagement confirms that many of today's employees care far less about a paycheck than they do the mission and purpose of their organization (Clifton \& Harter, 2019). The importance of designing work so that employees clearly understand their contribution to meaningful outcomes is a well-established principle (Saavedra \& Kwun, 2000). In identifying the importance of focusing on purpose rather than profits, Collins and Porras (2004) found that companies that emphasized their organizations' mission and the contribution to society were more financially successful than companies who emphasized generating profits. Emphasizing mission and purpose meets the needs of new employees who care about the contribution that they will be making to their companies and who want to know where they fit in contributing to an organization's objectives (Stein \& Christiansen, 2010).

\subsection{Inspire by Personal Example}

Successful leaders inspire a shared vision, encourage hearts, and model the way for employees (Kouzes \& Posner 2017). Employees -- and people in general -- watch their leaders. People watch what they do, how they act, what their integrity level is, what their ethics are (Kouzes \& Posner 2011). Leaders are so much more effective leading by example instead of pushing and directing others (Schein \& Schein, 2016). People will follow leaders who they trust to do the right thing - even when those leaders act at personal sacrifice to themselves (Caldwell \& Hasan, 2016; Block, 2013). When leaders do what they say they will do and demonstrate their dedication to achieving an organization's purposes, others follow their example (Collins, 2001).

\subsection{Hire World-Class Employees.}

A common mistake made by many companies is to fail to recognize the importance of hiring world class employees particularly when the quality of employees is critical to achieving a company's competitive success (Caldwell \& Anderson, 2018). In his landmark business book, Jim Collins (2001) repeatedly cited the critical importance of "getting the right people on the bus" as the most important factor in a company's success. Employees who are carefully selected and who work with top flight colleagues have a greater desire to raising the bar of their own performance and are also more focused on being partners in an organization committed to achieving excellence.

\subsection{Focus on Constant Learning}

Continual learning serves both the individual and the organization. Encouraging employees to constantly learn and grow is essential to creating an organization that innovates, that maintains technical skills, and that responds to the demands of constant change (Senge, 2006). Investing in employee training and development is a reflection of an organization's interest in employees' ability to enable a company to achieve its goals - as well as its acknowledgement of its commitment to employees' growth and development (Noe \& Kodwani, 2018). This investment conveys to employees an organization's recognition of its duty to all of its stakeholders and its recognition of the employees' role in fulfilling its responsibilities to them (DePree, 2004; Covey, 2004).

\subsection{Recognize Employee Commitment}

People are willing to increase their level of personal investment when they are recognized for what they strive to achieve and the dedication that they demonstrate (Kouzes \& Posner, 2003). A shortcoming of many managers is their failure to recognize employees' efforts and initiative. Organizational citizenship behavior, or the willingness to take initiative and go the extra mile, is widely recognized as a key quality that is essential for achieving a competitive advantage (Christensen, 2016; Beer, 2009; Pfeffer, 1998). Recognition of commitment is demonstrated by informal and informal expressions of thanks, by opportunities to learn and grow, by empowering employees, and by financial and non-financial perks (Kouzes \& Posner, 2003).

\subsection{Reward Team Achievements}

Publicly recognizing team achievements helps in providing cohesive team efforts and productivity (Levi \& Askay, 2020). Team rewards are most effective when organizations link performance with organization mission and purpose, customer satisfaction, and the contribution to profitability (Tombaugh, 2005). The practical reality of rewarding team efforts and achievements mirrors the fact that results are ultimately achieved by integrated efforts (Deming, 2000). Building team commitment by rewarding collective results is practical while reinforcing the importance of cooperation to achieve those outcomes (Friedley \& Manchester, 2005). 


\subsection{Pursue Long-Term Outcomes}

Employees who see their leaders make short-term decisions that undermine the long-term priorities of their organizations lose faith in those leaders. Conversely, employee loyalty to their organizations is strengthened when leaders demonstrate that they are committed to their employees' long-term success and careers (Pfeffer, 1998; Beer, 2009). Viewing employees as a temporary or part-time expense, rather than as a long-term stakeholder, conveys to employees that their relationship with an employer is simply a transactional exchange of money for performing a short-term task (Burns, 2010). Leaders who demonstrate that they care about a long-term purpose are perceived as ethical stewards worthy of being followed (Hernandez, 2012; Caldwell, Hayes, Bernal \& Karri, 2008).

\subsection{Demonstrate Emotional Awareness}

People want to be both understood and valued (Fromm, 2006). When a leader demonstrates by her/his actions that he cares about others and their welfare, (s)he establishes emotional connection (Goleman, 2005). Treating people humanely and with a commitment to their best interests creates a bond with them - recognizing that each person is a "You" and not an "It" (Buber, 1996; Atwijuka \& Caldwell, 2017). As leaders demonstrate Emotional Intelligence, they communicate that others matter and that leaders are aware of individuals' needs (Connors, 2020). When leaders who care authentically, the genuineness of that commitment is readily perceived by others (Atwijuka \& Caldwell, 2017).

\subsection{Honor Ethical Obligations.}

In a world where trust in leaders in organizations has typically declined (Harrington, 2017), leaders and organizations that honor their ethical obligations stand out. Unfortunately, more than half of all employees who responded to a 2018 survey about their leaders reported that they would be more likely to trust a complete stranger than the individuals for whom they worked (Sturt \& Nordstrom, 2018). Integrity, honesty, and keeping promises are vital characteristics of organizational leaders and the qualities that employees at all levels have identified as the key to credibility of their leaders (Kouzes \& Posner, 2011).

Consistent with the research suggested by other scholars, we recommend that leaders, managers, and supervisors recognize the need to adopt all nine of these behaviors if they are to be optimally effective in creating a culture where employee engagement can thrive (Pfeffer, 1998; Beer, 2009). Building on the research of scholars and the importance of each of these nine behaviors in contributing to employees' commitment to their organizations we define employee engagement as "the willingness and dedication of employees to an organization's purposes that is generated by their leaders' ability to create an organizational culture that values and develops employees, treats them as valued partners, and honors duties and responsibilities owed to them by establishing systems, policies, and practices that enable employees and their organization to become their best."

\subsection{The Ethic of Friendship}

The Ethic of Friendship has been recently written about as an ethical perspective associated with the relationships of individuals within a work context. Its principles are based upon treating others as friends to whom one owes a personal responsibility rather than just as impersonal individuals to whom no obligations are owed (Caldwell \& Anderson, 2021). To Aristotle, the highest type of friendship was not self-seeking but reflected genuine caring for another person and was the greatest form of friendship (Aristotle \& Irwin, 2019). In Aristotle's view, the foundation of ethics lies in its desire to help others - and without friends, life loses its fullest meaning (Kraut, 2001).

Consistent with Aristotle's view of friendship as goodness, Matousek (2013) described friendships as ethical partnerships that combine intimate commitment with authentic love. The expectations of friendship are that a good friend will care genuinely about one's best interests and that there is a mutual interest in the other person (Bennett, 2017). Authentic friends make an effort to make others feel comfortable and are committed to others' well-being and happiness (Sow \& Friedman, 2020). The primary quality of every friend is that (s)he is trustworthy - and trustworthiness is acknowledged to be "the 'make-or-break' element in any personal relationship" (Degges-White \& Van Tieghem, 2015).

In writing about a leader's obligations to her/his employees, James McGregor Burns (2010) is one of several leadership experts who have recognized that leaders best serve their organizations when they focused on melding the success of their organizations with the needs of their individual employees. Sharing a similar perspective, Max DePree (2004, p. 11) described the obligation to employees as a quasi-sacred "covenantal" relationship in which the leader must be both "a servant and a debtor" to others. DePree's description of the employer-employee association mirrors the definition of friendship offered by Anthony Robbins who wisely observed that true friends are there to give of themselves to others, rather than simply to take or to benefit from their association (Robbins, 1997). 
We define the Ethic of Friendship as "the commitment of a leader, manager, or supervisor within a work-related context to treat employees as valued friends, demonstrated by the individual's commitment to the employees' unique needs, their desire to grow and improve, and their best interests as members of the organization." The Ethic of Friendship confirms that leaders are perceived as most ethical by their employees when they are supportive and loyal to employees' needs. The standards of this ethic are sharply contrasted with the way that employees are currently treated in many organizations when those leaders adopt an arms-length and impersonal approach and treat employees like commodities. Comparing and contrasting the Ethic of Friendship with the broader and more encompassing Ethic of Care, the former is more narrowly focused on the employer-employee relationship and the responsibilities that are owed within that context (Caldwell \& Anderson, 2021). Both ethical perspectives address responsibilities owed, caring about others, and the importance of relationships - but the Ethic of Care is a more comprehensive moral standard that transcends the employer-employee context (Gilligan, 2016).

\section{Integrating the Concepts}

Table 1. Ethic of Friendship Nine Behaviors

\begin{tabular}{ll}
\hline \multicolumn{1}{c}{$\begin{array}{c}\text { Leader } \\
\text { Behaviors }\end{array}$} & \multicolumn{1}{c}{ Relationship to Ethic of Friendship } \\
\hline $\begin{array}{l}\text { Emphasize } \\
\text { Mission and } \\
\text { Purpose }\end{array}$ & $\begin{array}{l}\text { Focusing employee efforts on the outcomes and purposes that } \\
\text { they are being asked to achieve helps employees to appreciate } \\
\text { the significance of their work and the importance of the } \\
\text { organization's role in society. Creating a shared ownership } \\
\text { in the pursuit of these goals strengthens team culture and } \\
\text { loyalty. }\end{array}$ \\
\hline $\begin{array}{l}\text { Inspire by } \\
\text { Personal }\end{array}$ & $\begin{array}{l}\text { Leaders who ask employees to follow their personal example } \\
\text { create a personal connection and a feeling of mutual } \\
\text { ownership with others. }\end{array}$ \\
\hline
\end{tabular}

\section{Hire World Class Employees \\ Caring about the entire organization and its success is more likely to be demonstrated when leaders hire individuals who are capable, competent, and committed.}

\begin{tabular}{ll}
\hline Focus on & Leaders who invest in their employees' growth and success \\
Constant & honor their employees and show employees by their \\
Learning & investment that they care about their achievements.
\end{tabular}

Recognize Because individuals who go the extra mile are worthy of

Employee

Commitment recognition and acknowledgement, making the effort to say "Thank you" and to recognize that commitment demonstrates that leaders care at the personal level.

Creating a culture that rewards team achievements build esprit within that team and emphasizes cooperation rather

Reward Team Achievements than competition. Rewarding team efforts increases a culture of mutual effort.

Pursue

Long-term

Outcomes

Friendship relationships care about others' long-term welfare and progress. Committing to long-term objectives is consistent with the responsibilities of friendship and the needs of all stakeholders.
Building a sense of organizational purpose and shared investment in a worthy pursuit is often a critical element that not only builds teamwork but that bonds a feeling of organizational dedication and responsibility.

Asking employees to work hard for a shared goal has its greatest impact when leaders work side-by-side and support colleagues in a shared effort.

Being part of a highly-qualified and mutually supportive team inspires confidence, builds commitment to the team, and increases dedication.

Friends care about other friends' successes and demonstrating a commitment to others' improvement shows that caring.

Individuals are far more likely to respond to others who create personal relationships with them and acknowledging hard work, effort, and initiative builds that personal relationship.

Sharing the benefits of the organization's success with employees at all levels of that organization is logical, fair, and equitable. Friends treat each other in that same way.

When leaders focus on achieving long-term goals, they communicate to others their commitment to long-term relationships and their recognition of the need to sustain an organization

Friends are sensitive to the needs of those whom they care about and demonstrate that awareness by being empathic and compassionate.

True friendship is always genuine, ethical, and authentic. Friends respect each other and seek mutual interests. 
By adopting the Ethic of Friendship in their relationships with employees, leaders and managers acknowledge their ethical obligation to treat employees so well that those individuals come to recognize their highest potential and strive to achieve it (Covey, 2004, pp. 98-99). Honoring this ethical responsibility integrates elements of servant leadership, transformational leadership, transformative leadership, level 5 leadership, charismatic leadership, and covenantal leadership (Caldwell, 2012) as well as the ethics of universal rules, universal rights, utilitarian ethics, virtue ethics, and transformative ethics (Al Lawati, Sayed, \& Caldwell, 2019). Table 1 identifies how the Ethic of Friendship addresses the nine behaviors associated with the nine leadership behaviors that help to create employee engagement.

As indicated by Table 1, when leaders are motivated by the Ethic of Friendship, their actions are closely aligned with the nine behaviors that we have described as important in creating employee engagement.

\section{Contributions of the Paper}

As leaders in today's organizations strive to be effective in accomplishing their organization's purposes, serving their customers, and honoring their obligations to society, creating a culture that encourages and supports the engagement of employees as full partners has been widely recognized as a critical priority (Clifton \& Harter, 2019; HR Research Institute, 2019). We suggest that this paper adds four important contributions to the scholarly literature while also providing important insights for managers, supervisors, and leaders.

1). We provide a more detailed working definition of employee engagement that builds upon the scholarly literature and current research. The definition that we provide acknowledges both the employee's active commitment and the obligations of leaders and managers.

2). We provide a definition of the Ethic of Friendship as an ethical obligation of leaders of organizations. Although the Ethic of Friendship has been addressed in other academic papers and textbooks, to our knowledge, the Ethic of Friendship has not previously been defined as an important ethical guideline for leaders and organizations.

3). We identify nine important behaviors of leaders, managers, and supervisors to enhance employee engagement. These nine behaviors are consistent with the importance of aligning management practices, and their significance is consistent with other academic and practitioner research.

4). We integrate nine behaviors of leaders that promote employee engagement with the principles of the Ethic of Friendship. Integrating the Ethic of Friendship with the behaviors that promote employee engagement provide leaders with an ethical framework for guiding them as they seek to create a culture of engagement that enhances competitive advantage.

These four contributions are worthy of thoughtful study and discussion by scholars and practitioners and have great practical value in increasing employee commitment and trust in leaders.

\section{Conclusion}

There are no magic solutions or guarantees to achieving competitive success (Quinn, 1996). Earning the trust of employees and creating a culture which treats them as valued assets, rather than as exchangeable parts, make it possible for leaders and managers to reverse the worldwide trend wherein trust and commitment are often missing in organizations. What leaders and managers seem to forget is that each employee deserves to be treated humanely and humanly. Failing to recognize the importance of fully engaging employees as owners and partners in an organization's success is a choice that is ultimately contrary to the best interests of both that organization and its leaders (Block, 2013).

Although adopting the Ethic of Friendship does not replace competence, good judgment, and technical expertise as important elements in creating competitive advantage or organizational sustainability, when the Ethic of Friendship is adopted and the nine behaviors of employee engagement are combined with those other important factors, organizations are likely to be far more profitable (Pfeffer, 1998; Beer, 2009). As organizational leaders and managers reflect on their roles in organizations, we respectfully suggest that adopting the Ethic of Friendship and the nine integrated behaviors of employee engagement will not only improve their relationships with employees and increase employee trust but also enable their companies to be more successful.

\section{References}

Aristotle, \& Irwin, T. (2019). Nichomachean Ethics (3rd ed.). Indianapolis, IN: Hackett Publishing.

Al Lawati, H. A. H., Sayed, R. T., \& Caldwell, C. (2019). Transformative Ethics and Moving Toward 'Greatness.' Problems and Realities. Journal of Values-Based Leadership. XII(1). https://doi.org/10.22543/0733.121.1259 
Atwijuka, S., \& Caldwell, C. (2017). Authentic Leadership and the Ethic of Care. Journal of Management Development, 36(8), 1040-1051. https://doi.org/10.1108/JMD-12-2016-0331

Barnard, C. I. (1938). The Functions of the Executive. Cambridge, MA: Harvard College.

Beer, M. (2009). High Commitment, High Performance: How to Build a Resilient Organization for Sustained Advantage. San Francisco, CA: Jossey-Bass.

Bennett H. (2017). "Friendship." The Stanford Encyclopedia of Philosophy. E. N. Zalta (ed.). Found online on January 21, 2021 at Friendship (Stanford Encyclopedia of Philosophy).

Block, P. (2013). Stewardship: Choosing Service Over Self-Interest. San Francisco, CA: Jossey-Bass.

Buber, M. (1996). I and Thou. New York: Scribner Publishing.

Burns, J. M. (2010). Leadership. New York: Harper Perennial.

Caldwell, C., \& Anderson, V. (Eds.). 2021. Justice for All. Hauppage, New York: NOVA Publishing.

Caldwell, C., \& Hasan, Z. (2016). The Covenantal Leader - Honoring Implicit Relationships with Employees. Graziadio Business Review, 19(2). Retrieved from http://gbr.pepperdine.edu/2016/10/the-covenantal-leader

Caldwell, C., Hayes, L., Karri, R., \& Bernal, P. (2008). Ethical Stewardship: Implications for Leadership and Trust. Journal of Business Ethics, 78(1/2), 153-164. https://doi.org/10.1007/s10551-006-9320-1

Cameron, K. S. (2012). Positive Leadership: Strategies for Extraordinary Performance (2nd ed.). San Francisco, CA: Berrett-Koehler Publishers.

Christensen, C. M. (2016). The Innovator's Dilemma: When New Technologies Cause Great Firms to Fail. Boston, MA: Harvard Business Review Press.

Clifton, J., \& Harter, J. (2019). It's the Manager. Omaha, NE: Gallup Press.

Collins, J. (2001). Good to Great: Why Some Companies Make the Leap . . . And Others Don't. New York: HarperCollins.

Connors, C. D. (2020). Emotional Intelligence for the Modern Leader. Emeryville, CA: Rockridge Press.

Degges-White, S., \& Van Tieghem, J. P. (2015). Toxic Friendships: Knowing the Rules and Dealing with the Friends Who Break Them. Lanham, MY: Rowman \& Littlefield.

Deming, W. E. (2000). Out of the Crisis. Cambridge, MA: MIT Press.

DePree, M. (2004). Leadership is an Art. New York: Crown Publishing.

Erickson, T. J. (2005). Testimony submitted before the US Senate Committee on Health, Education, Labor and Pensions. May 26, 2005.

Friedley, S. A., \& Manchester, B. B. (2005). Building Team Cohesion: Becoming "We" Instead of "Me." National Forensic Journal, 20(1), 95-100.

Fromm, E. (2006). The Art of Loving. New York: Harper Perennial.

Gilligan, C. (2016). In a Different Voice: Psychological Theory and Women's Development. Boston, MA: Harvard University Press.

Goleman, D. (2005). Emotional Intelligence: Why It Can Matter More Than IQ. New York: Bantam.

Harrington, M. (2017). Survey: People's Trust Has Declined in Business, Media, Government, and NGOs. Harvard Business Review, January 16, 2017 and found online on January 21, 2021 at For the First Time in 17 Years, People's Trust Declined in Every Kind of Institution We Asked About (hbr.org)

HR.Research Institute. (2019). The State of Employee Engagement in 2019. Aurora, Canada: HR.com.

Kouzes. J. M., \& Posner, B. Z. (2003). Encouraging the Heart: A Leader's Guide to Rewarding and Recognizing Others. San Francisco, CA: Jossey-Bass.

Kouzes. J. M., \& Posner, B. Z. (2017). The Leadership Challenge: How to Make Extraordinary Things Happen in Organizations (7th ed.). San Francisco, CA: Jossey-Bass.

Kouzes. J. M., \& Posner, B. Z. (2011). Credibility: Why Leaders Gain and Lose It, Why People Demand It. San Francisco, CA: Jossey-Bass. https://doi.org/10.1002/9781118983867 
Kraut, R. (2018). “Aristotle's Ethics.” Stanford Encyclopedia of Philosophy. E. N. Zalta (ed.). Found online on January 21, 2021 at Aristotle's Ethics (Stanford Encyclopedia of Philosophy).

Macey, W. H., \& Schneider, B. (2008). The Meaning of Employee Engagement. Industrial and Organizational Psychology, 1(1), 3-30. https://doi.org/10.1111/j.1754-9434.2007.0002.x

Matousek, M. (2013). Ethical Wisdom for Friends: How to Navigate Life's Most Complicated, Curious, and Common Relationships. Deerfield Beach, FL: HCI Publishing.

Noe, R., \& Kodwani, A. D. (2018). Employee Training and Development. Delhi, India: McGraw-Hill Education.

Quinn, R. E. (1996). Deep Change: Discovering the Leader Within. San Francisco, CA: Jossey-Bass.

Robbins, A. (1997). Unlimited Power: The New Science of Personal Achievement. New York: Free Press.

Saks, A. M., \& Gruman, J. A. (2014). What Do We Really Know About Employee Engagement? Human Resource Development Quarterly, 25(2), 155-182. https://doi.org/10.1002/hrdq.21187

Schein, E. H., \& Schein, P. A. (2016). Organizational Culture and Leadership (6th ed.). San Francisco, CA: Jossey-Bass.

Senge, P. M. (2006). The Fifth Discipline: The Art \& Practice of the Learning Organization (2nd ed.). New York: Image Books.

Stein, M., \& Christiansen, L. (2010). Successful Onboarding: Strategies to Unlock Hidden Value in Your Organization. Boston, MA: McGraw-Hill Education.

Sturt, D., \& Nordstrom, T. (2018). 10 Shocking Workplace Stats You Need to Know. Forbes, March 8, 2018 and found online on January $21, \quad 2021$ at https://www.forbes.com/sites/davidsturt/2018/03/08/10-shocking-workplace-stats-you-need-to-know/\#2a90c89 $2 \mathrm{f} 3 \mathrm{af}$

Tombaugh, J. R. (2005). Positive Leadership Leads Performance and Profitability. Development and Learning in Organizations, 19(3), 15-17. https://doi.org/10.1108/14777280510590031

\section{Copyrights}

Copyright for this article is retained by the author(s), with first publication rights granted to the journal.

This is an open-access article distributed under the terms and conditions of the Creative Commons Attribution license (http://creativecommons.org/licenses/by/4.0/). 